\title{
SUBJETIVIDAD FEMENINA MÁS ALLÁ DE LA DIFERENCIA ANATÓMICA DE LOS SEXOS
}

\author{
Laura Elena A. Ferrón Martínez
}

\section{Introducción}

“¿Qué quiere una mujer?”, preguntó Freud. “La Mujer No Existe” dijo Lacan. “El psicoanálisis es partícipe del Fin del Dogma Paternal”, menciona Michel Tort, psicoanalista francés. La mayoría de los escritos sobre las mujeres en el psicoanálisis clásico son escritos por hombres. Si bien han existido figuras como Klein, Horney, Anna Freud, Joan Rivière, Françoise Dolto y otras muchas psicoanalistas, sus nombres figuran en segundo término. Los padres del psicoanálisis (Freud y Lacan para algunos) siguen siendo varones. De ahí que la teoría psicoanalítica, nacida en una época previa a la liberación femenina, ha planteado sesgos en sus explicaciones sobre las mujeres y la feminidad. En la clínica, encontramos aún casos que nos remiten a las historias relatadas por Freud en la Viena victoriana, pero también se escuchan otros discursos que contradicen las enseñanzas del Padre Freud. De ahí la necesidad de detenerse entre la teoría y la clínica a preguntarse por las mujeres, nuestras pacientes, nuestras colegas, las mujeres de nuestra cultura, de nuestro país y del mundo.

En el discurso patriarcal, las mujeres ocupan un lugar denigrado sosteniendo los ideales de la masculinidad. A pesar de las críticas al psicoanálisis como discurso patriarcal y androcéntrico, es imposible negar que Freud fue pionero en escuchar a las mujeres y conceptualizarlas como sujetos. Es por esto lo que inicialmente se expondrán algunos desarrollos psicoanalíticos sobre la construcción de la subjetividad femenina. Posteriormente se utiliza la teoría psicoanalítica para un análisis del imaginario social y cultural de la mujer mexicana, recurriendo a la leyenda de Malinche. Finalmente, se presenta una propuesta para el abordaje de la problemática contemporánea del ser mujer 
vinculando la carga histórica, social y cultural así como la situación de vida subjetiva y particular de cada mujer.

\subsection{Mujeres en el discurso}

La filosofía y el conocimiento fueron por muchos siglos un asunto de hombres. La historia de la humanidad ha sido también una historia del hombre, donde las mujeres habían sido solo un objeto de referencia. "Las mujeres han estado en el límite de los campos del conocimiento, sin embargo, siempre se les mantiene como una imagen, como la representación de los valores masculinos” (Fraisse, 1996: 13). El lugar de las mujeres ha sido el de la representación, han sido símbolos en un mundo de conocimiento masculino. Han sido también objetos; objetos de amor, de rechazo, de agresión, objetos de moda, de apariencia, objetos de belleza, de lujuria; objetos sexuales. "La mujer puede ser sujeto mientras se mantenga en el lugar de objeto”(Fraisse, 1996: 14). Un objeto sometido a su condición sexual.

En nuestra época, la sociedad atraviesa momentos importantes de cambio. Y uno de los cambios que se ha gestado desde el siglo XVII es el llamado movimiento feminista. Mas allá de los factores políticos y económicos que conlleva el movimiento de las mujeres, en la subjetividad de ambos sexos, las mujeres se han movido de lugar. ¿Qué sucede cuando el objeto habla? ¿Qué pasa cuando los objetos deciden definirse a sí mismas como sujetos? ¿Cómo reacciona el mundo de los hombres? Definitivamente, esto es vivido como una amenaza a su poder y su conocimiento (Fraisse, 1996: 16, citando a Kierkegard, 1984, y a Shopenhauer, 1980). Por el otro lado, para las mujeres, también implica una lucha para ganarse un lugar como sujetos en un mundo que las inscribe como objetos. Es una cuestión de lucha social entre los sexos con respecto a la identidad individual de las mujeres que impacta tanto a los varones como a las mujeres mismas en lo cultural y en la representación de la feminidad.

Aunque el género es un concepto nuevo, no utilizado en los inicios del psicoanálisis con el significado que tiene en nuestros días, Freud inició sus estudios y 
descubrimientos sobre el inconsciente a partir de preguntarse: ¿Qué quiere una mujer? Los estudios sobre la histeria versan todos sobre dicha pregunta. Lacan a su vez, 50 años después, se pregunta qué es una mujer?, enunciando la pregunta histérica.

En la sociedad contemporánea no solo es vigente preguntarse qué es o qué quiere una mujer, sino también qué es y qué quiere un hombre? ¿Cómo redefinir los conceptos y los imaginarios sociales alrededor de la diferencia de los sexos? Socialmente es evidente que no hay un consenso general al respecto. Y en la clínica, en lo individual, aparecen serias confusiones sobre la identidad (¿quién soy?, ¿qué soy?, ¿soy?) y la identidad de género (¿qué es ser hombre?, ¿qué es ser mujer?).

A pesar de los estudios contemporáneos, la teoría psicoanalítica sigue siendo un discurso androcéntrico en el cual no hay un significante para la mujer (La Mujer no existe), la sexualidad femenina se significa a partir de los fantasmas histéricos de la pasividad y el fantasma de la maternidad. Así mismo, el hombre se significa para la histérica como el fantasma del Padre primordial, y efectivamente, no hay relación sexual. La razón que fundamenta estas afirmaciones es que la teoría psicoanalítica es un discurso de los hombres (a través del discurso de El Analista o del discurso de El Amo) tratando de hablar de las mujeres (interpretando o tratando de entender el discurso de La Histérica). Recordemos que Lacan plantea los fantasmas como significantes que recubren la falta en lo Simbólico. Así, muchos de los conceptos teóricos en psicoanálisis ocultan relaciones de poder entre los sexos fundamentadas en esquemas sociales, culturales y en el pensamiento occidental.

Michel Tort (2005: 32) denuncia en este sentido que “el psicoanálisis transforma en mito la organización de la familia moderna a partir de la normalización de Edipo”. El mismo autor señala como la teoría psicoanalítica ha sostenido el lugar simbólico del padre frente a su inminente caída a fines de la revolución francesa. Tort (2005: 30) plantea que el patriarcado es una construcción política para mantener el poderío masculino y legalizar el sometimiento de las mujeres y los infantes. 


\section{Las mujeres del psicoanálisis}

El psicoanálisis nace a partir de los estudios sobre la histeria. Los maestros de Freud en psicoanálisis fueron sus pacientes, la mayoría mujeres, quienes sufrían de histeria. En los principios de su investigación, Freud comete un enorme error que ha plagado a la teoría psicoanalítica desde entonces y a la fecha: asociar la histeria a la feminidad. Como lo indica Juliet Mitchell (2000), “la histeria se convirtió en feminidad”.

Freud creó una serie de significantes para la feminidad, relacionándola con la histeria y finalmente a la pasividad. Para Freud, ser femenino era ser pasivo, mientras que ser masculino era ser activo. De acuerdo con él, la pasividad es siempre rechazada y por lo tanto, lo femenino es lo primordialmente reprimido para ambos sexos. En 1896, Freud (1980: 167) escribe que “debemos sospechar que lo esencialmente reprimido es siempre lo femenino”. Si el núcleo de lo reprimido es lo femenino, ejercido por la represión primaria, entonces, efectivamente, no hay lugar para La Mujer en Lo Simbólico, ya que lo primordialmente reprimido pertenece a Lo Real. En estos términos, la pasividad es un significante para la feminidad que cubre el hueco de la falta de La Mujer en Lo Simbólico. Como lo indica Paul Verhaeghe (1997: 55): "Freud había descubierto la falta en el orden Simbólico: no existe un significante para La Mujer”.

Esto explica por qué la historia (un discurso patriarcal) siempre ha dejado a las mujeres de lado; rechazadas, reprimidas, como objetos sin posibilidad de convertirse en sujetos. El deseo de La Mujer no es reconocido ya que recuerda el deseo de La Madre que vuelve a los hombres en objetos (así como el niño/a es el objeto de deseo de la madre). A pesar de que no hay un significante para La Mujer, existe uno para La Madre. La Madre es el objeto original, del cual el sujeto trata de escapar a través de la identificación con el padre como el Otro quien puede separarlo del vínculo y del deseo omnipotente de ella. Partiendo de la premisa inicial de que los sujetos luchan por ser reconocidos como tales. 
El proceso de convertirse en sujeto es un tránsito de Lo Real a Lo Simbólico. Para los hombres es un paso un tanto sencillo: se identifican con la masculinidad del padre y reprimen la feminidad: a La Madre-Mujer: lo femenino. La castración protege al sujeto del misterio de la feminidad (la feminidad de La Madre pre-edípica) constituyendo una línea divisoria entre las dos dimensiones del placer: el goce del Otro (goce de La Madre en el cual el niño/a es su objeto de deseo) y el goce fálico (goce del sujeto). El primero pertenece a Lo Real, donde el sujeto se desvanece en el Otro; el segundo se expresa a través del falo. Así, la castración y el reconocimiento de la diferencia entre los sexos son condiciones necesarias para el goce fálico.

Ya que el significante para La Mujer no existe, los únicos significantes posibles para las hembras son La Histérica y La Madre. Por lo que solo hay dos opciones para la hembra: convertirse en histérica o en madre. Sin embargo, ninguna de estas opciones la lleva a ser Una Mujer.

Para Lacan (1956: 229-260), La Mujer es el único ser que está dentro y fuera de la Ley al mismo tiempo, haciendo La Ley relativa. Por lo que el proceso de convertirse en mujer es una forma de creatividad, una transformación en términos de sublimación. La mejor forma de enfrentar la falta del significante (en este caso, el significante para La Mujer) es encontrando otro significante (ya sea el histérico, la madre o la identificación con el padre que llevaría a la denegación de la castración y de la diferencia de los sexos). Esto hace que la perspectiva de la identidad femenina sea siempre reduccionista.

\subsection{La representación de la Feminidad: reconsiderando la histeria}

El problema para las mujeres es que tienen que asumir una identidad para la cual no hay un significante en Lo Simbólico. Por lo tanto, la identidad femenina es un asunto de lo Imaginario. Como lo indica Simone de Beauvoir (1949: 15): "No se nace mujer: llega una a serlo”. El proceso de convertirse en sujeto sin un significante al cual referirse hace que las mujeres se identifiquen con el único significante posible: el falo. 
Freud fue un pionero en referirse a las mujeres como posibles sujetos. Sugirió que la diferencia anatómica entre niños y niñas marca la superioridad del niño, sin embargo, las niñas tienen la posibilidad de envidiar el pene e identificarse con el padre (lo que Lacan diría es el camino hacia el Orden Simbólico y a convertirse en sujetos). Freud dio a las mujeres la posibilidad de lo que Lacan llama deseo; un objeto no puede desear, un sujeto sí.

A pesar de que la perspectiva de Freud con respecto al ser mujer es aún parcial, el psicoanálisis definitivamente cambió la perspectiva de la mujer en el conocimiento moderno (Fraisse, 1996: 109-110). De acuerdo a Freud (1933), para la niña, así como para el niño, la madre es el primer objeto de amor y para volverse al padre, ella tiene que separarse primero de la madre (Freud, 1980: 104-126). Para Freud, la separación de la madre ocurre a través de la aceptación de la diferencia entre los sexos y el complejo de castración. En este punto, la niña pasa por tres fases en su conflicto edípico.

Inicialmente Freud propone que la niña insiste en su masculinidad, a través de la denegación de la diferencia entre los sexos, la vista del pene del niño y manteniéndose en una relación simbiótica con la madre. Al utilizar el mecanismo de la denegación, en vez de la represión, esta opción llevaría a una estructura de tipo perverso (Fink, 1996: 166). En este orden de ideas, la niña fijada en esta fase desarrollará una feminidad fálica. Tal es el caso de la Joven Homosexual en Freud, o como se explicará más adelante, de las pacientes (consideradas histéricas) transgresivas (Rivière, 1929). Autores como Joan Rivière, Karen Horney, Jessica Benjamín, Donna Bassin y Louis Kaplan han explicado la feminidad desde esta perspectiva.

En un momento del desarrollo, la niña desiste de su masculinidad y aparece la envidia del pene. La aceptación de la castración y la envidia del pene separan a la niña de la madre, ya que la culpa por haberla castrado. La niña se separa de la madre por enojo con ella. La fijación en esta fase lleva a una feminidad conflictuada con lo femenino y con la Madre. Tal es el caso de Dora en Freud. Autores como Klein y Emilice Dio Bleichmar (1985) han abordado ampliamente esta temática del conflicto femenino. 
Finalmente, al separarse de la madre y para lograr tener un pene, la niña elige al padre como su objeto de amor esperando tener su pene. Así, la madre se convierte en su rival, ya que el padre es pareja de la madre. Esta es la opción que Freud ofrece para un desarrollo heterosexual sano. Sin embargo, la fijación en esta etapa lleva a la niña a desarrollar defensas neuróticas contra su deseo incestuoso hacia el padre, siendo la represión el mecanismo más importante. Esta opción llevará a la concepción clásica de la feminidad en la cultura occidental donde las mujeres se quedan como objetos de deseo. Esta posición es congruente con el Discurso de la Histérica de Lacan y la versión clásica de la histeria.

\subsection{Identidad y subjetividad femenina}

En un mundo donde los sujetos son masculinos, muchas mujeres han tenido que identificarse con la posición masculina para ser reconocidas como sujetos. Esto lleva a la primera fase en el Complejo de Edipo planteado por Freud, o al concepto en Horney de la "huida de la feminidad" (flight from womanhood), para explicar la persistencia de la envidia del pene (complejo de masculinidad) y la insistencia de la niña en ser como el padre (o ser el padre) en vez de tenerlo heterosexualmente. Esta estrategia es, sin embargo, falsa. Las mujeres que efectivamente se identifican con hombres presentan severos conflictos internos que las lleva a crear lo que Rivière (1929) denominó la mascarada femenina (womanliness masquerade). Rivière indicaba cómo la mascarada femenina es utilizada para ocultar la posesión de la masculinidad y disminuir las posibles represalias por poseerla, siendo un acting culposo por haber trasgredido la posición del padre y tener su falo.

Para una mejor explicación de este fenómeno es importante tomar en cuenta que la importancia de la identificación de la niña con el padre (o el tomar su lugar) se basa en una necesidad de separarse de la madre pre-edípica. El padre y el falo representan un poder independiente de la madre. Jessica Benjamin (1991: 277-299) ha sugerido que los imperativos psicológicos del narcisismo primario y el proceso de 
separación-individuación llevan al niño a investir al padre y al falo con atributos idealizados que son cruciales para el desarrollo sexual y el desarrollo del self. Ya que la lucha por diferenciarse se entrelaza con la consolidación de la identidad de género, la lucha por ser reconocido como un ser independiente de la madre es la base para el establecimiento de la identidad femenina.

En este punto, la niña no solo necesita, también quiere, desea. Desear le da subjetividad. Cada expresión concreta de querer encuentra en su origen el deseo general de querer ser reconocido en el propio deseo; de ser reconocido como un sujeto deseante y no como un sujeto necesitado, o bien como un objeto del deseo de la madre. Durante este proceso de separación-individuación, el conflicto entre la identificación con el padre o con la madre comienza a simbolizarse. Las dos necesidades irreconciliables comienzan a formularse como una escisión de género: la madre (y la identificación con ella) representa el apego y el padre (y la identificación con él) representa el reconocimiento de la independencia.

En este punto, el padre representa un tipo distinto de objeto quien será el espejo del deseo. El representa un sujeto que puede querer y actuar de manera adecuada para lograr lo que quiere. Por lo que identificarse con el padre es una forma de convertirse en sujeto deseante. Pero la identificación con el padre para la niña tiene una connotación adicional ya que debe negar su identidad como hembra. La identificación con la masculinidad es una traición a la feminidad que lleva a la culpa.

Las mujeres que se identifican con el rol masculino o asumen al rol paterno presentan un sabotaje constante a su condición de sujetos. La paciente de Rivière es un ejemplo de una mujer profesionalmente exitosa que sabotea su éxito profesional a través de su sexualidad. Parece que las mujeres no han escapado de su definición como el Belle Sex. Aún pesa sobre ellas la sombra de ser objetos sexuales. En la clínica es fácil encontrar abundantes referencias a este aspecto.

El conflicto crucial para la formación de la identidad femenina es el reconocimiento de la mujer como sujeto, cuando histórica y culturalmente, las mujeres han sido representadas como objetos. Y aún más, como se indicó anteriormente, no 
existe un significante para La Mujer en Lo Simbólico. Dadas las circunstancias, pareciera que la única opción de las mujeres es un cambio de posición para volverse sujetos a partir de una identificación de género cruzado (cross-gender identification) con lo masculino. Esto conlleva a una contradicción entre el sexo biológico y el rol o estereotipo de género. Siguiendo con lo anterior, las mujeres identificadas en lo masculino tendrán que representar una mascarada femenina para ocultar esta contradicción.

A este respecto, Louise Kaplan (1941) plantea que los estereotipos de género socialmente normalizados son utilizados en la infancia como solución a los problemas infantiles, es decir que el niño recurre a los ideales de género para confirmar su naciente identidad sexual. Del mismo modo, la autora señala que en las perversiones femeninas "los estereotipos genéricos sociales, mutiladores desde el punto de vista psicológico, se alían con los ideales infantiles" (Kaplan, 1941: 26) por lo que "las perversiones femeninas se manifestarán en conductas que imitan y caricaturizan un ideal genérico femenino" (Íbid.).

Donna Bassin (1985) ofrece una explicación de como "la identidad de género puede ser un engaño cuando ésta se utiliza como protección contra los deseos conflictivos y algunos aspectos del self. Esta identidad protectora puede llevar a la culpa o la vergüenza ya que una parte del Yo reconoce el engaño" tal como sucede en el caso descrito por Riviere, la descripción de Kaplan y en el carácter histérico. Según Wilhelm Reich (1929: 102), el carácter histérico presenta un comportamiento sexual evidente, con un lenguaje corporal específico que es definitivamente sexualizado; cambios repentinos en el comportamiento, una actitud de coqueteo disfrazado, inconstancia en las reacciones emocionales, susceptibilidad a la sugestión, tendencia a la decepción, y una vivida imaginación que lleva a la mentira patológica. Esto sostiene la idea de que el carácter histérico encontrado en pacientes como la de Rivière es una defensa ante la identificación de género cruzado.

Freud indica en los Tres Ensayos (1905) que la histeria es una defensa ante la culpa o la vergüenza de pretender tener el falo. El carácter histérico es una defensa ante 
un conflicto derivado de la sexualidad infantil perversa donde la diferencia entre los sexos y la castración son denegadas. De ahí que la histeria se normalice como feminidad o bien que la observación hecha por Freud (1895) en de que "la pasividad sexual natural de la mujer explica su predilección con la histeria” parezca vigente en la clínica.

Bassin plantea una posible solución al conflicto de la identificación de género cruzado a través de la integración de lo femenino con lo masculino en el contexto de una identidad femenina diferente. Bassin sugiere que "el conflicto bisexual puede manejarse mas que reprimirse trascendiendo las posiciones sexuales normativas, rígidas y polarizadas sin necesidad de caer en la exageración del estereotipo de género, las perversiones femeninas o los conflictos de identidad de género”. Ella plantea que

la polarización de los núcleos de la identidad de género y la habilidad para simbolizar libremente y acoger las fantasías y representaciones del género cruzado no son opciones que se tengan que escoger de manera obligatoria -la mente puede jugar con la realidad, simbolizarla y crear identificaciones imaginativas y empáticas de los comportamientos de género cruzado. Los símbolos funcionan para reconciliar el dilema de la bisexualidad, las decepciones con respecto a la castración y otros límites, sin la necesidad de recurrir a la represión patológica o las estrategias perversas. Cuando una parte polarizada del conflicto no es simbolizada, se recurre al mecanismo de identificación proyectiva, como la percepción del Otro como castrado o poseedor del falo dominante. (Bassin, 1985: 158-159)

Esto remite a las imágenes de los varones que muchas mujeres traen a sus análisis: ya sean hombres devaluados o bien monstruos omnipotentes y feroces (Ferrón, 2006). Finalmente, Bassin concluye que "la entrada a la fase genital femenina requiere la integración, aceptación y elaboración simbólica de la sexualidad y diferencias anatómicas de ambos sexos en la psique” (Bassin, 1985: 159). Tal vez a esto se refería Simone de Beauvoir al decir que las mujeres no nacen, se hacen.

El argumento que plantea Bassin parece resolver el dilema de la identidad femenina en una reconciliación con la masculinidad y la construcción de las mujeres como sujetos y no como objetos. Sin embargo, ¿cómo puede algo ser simbolizado si no 
hay un significante para éste? Visto de esta forma, no se trata de convertirse en mujer, sino de inventarse una nueva forma de ser mujer integrando lo femenino y lo masculino, lo que requiere un proceso creativo y acaso sublimatorio.

Queda un último problema por resolver: el de la representación social y cultural de una nueva feminidad. Lo cual llevaría a cuestionar ahora la identidad masculina en tanto las mujeres tomen un lugar como sujetos. Lo cual lleva necesariamente a los varones a moverse en una dinámica similar en la que se ven forzados a incorporar su parte femenina a su identidad como varones (Ferrón, 2006).

Este análisis refleja un problema nuclear para la humanidad: la aceptación de la coexistencia de lo pasivo y lo activo, más allá de los significantes del género, lo que implica el rompimiento de la asociación femenino-pasivo y masculino-activo. El principal problema no es el género, ni la sexualidad, sino la ecuación entre pasivo y activo. La razón por la cual lo pasivo (no La Mujer ni la feminidad) es lo primordialmente reprimido es relativamente sencilla y encuentra sus orígenes en la inmadurez biológica del cachorro humano. Este cachorro indefenso, biológicamente mal equipado (en comparación a otros animales), depende por completo de su madre para sobrevivir. El bebe humano (de ambos sexos) nace en un estado de pasividad casi total frente a La Madre (una hembra) quien será un Otro. Ante la amenaza de desaparecer en el deseo del Otro (La Madre), el cachorro se ve en la necesidad de moverse a una posición activa. La lucha por convertirse en un sujeto con deseo y no un objeto de deseo lo lleva a separarse de la madre omnipotente. Utilizando mecanismos de defensa primitivos, la ansiedad que genera el miedo a la aniquilación es desplazado a la posición pasiva; y la figura ambivalente de La Madre (capaz de dar la vida pero también la muerte) es desplazada a La Mujer. Es La Madre, no La Mujer quien es primordialmente reprimida. Es el miedo a la aniquilación (más cercano a la pulsión de muerte) y no la pasividad lo que se pretende evadir. Este es el origen del proceso de convertirse en sujeto para ambos sexos.

Para la mujer es doblemente difícil, ya que además de ser bebé, es hembra, con una identificación narcisista con aquella, La Madre, temida, repudiada, amada e 
idealizada. González de Chávez explica a partir del análisis de los mitos y rituales sobre el cuerpo femenino que "la potencia femenina (materna, reproductiva y erótica) debe ser aniquilada para que el varón pueda afirmar su masculinidad” (González de Chávez, 1998: 88).

\section{El Imaginario cultural mexicano: vírgenes y prostitutas}

A continuación utilizaré el contexto de la cultura mexicana para ejemplificar los desarrollos teóricos descritos en el apartado anterior en la interpretación del mito de La Malinche. La fuente principal de los desarrollos teóricos sobre la psicología del mexicano son los trabajos de Díaz-Guerrero (1976).

En la sociedad mexicana, como otros países Latinoamericanos, los hombres tienen primacía sobre las mujeres. El mundo de los hombres ha hecho de la mujer un mito donde se le considera un ser de segunda clase, un objeto sexual que puede ser explotado y humillado. Las observaciones planteadas por Fraisse parecen ejemplificar de manera clara en el imaginario social mexicano. Resulta interesante hacer una investigación histórica para comprender cómo es que las mujeres mexicanas asumen este papel en pleno siglo veintiuno, era del post feminismo y la liberación femenina. Las ideas, expresiones y conductas del modelo de feminidad impuesto por paradigmas culturales masculinos determina que las mujeres deben ser dulces, trabajadoras, sinceras, madres, amantes y esposas abnegadas. De lo contrario, son satanizadas como traidoras de los valores morales, ambiciosas, prostitutas: seres malignos. En ambas versiones, las mujeres nunca aparecen como seres humanos en el discurso.

Desde las raíces culturales, la mujer se ha representado en el imaginario social mexicano en una actitud de dependencia y sumisión hacia el varón (Díaz-Guerrero, 1976) ${ }^{1}$. Esta actitud comienza con la relación con el padre, continúa en la relación con los

\footnotetext{
${ }^{1}$ Un claro ejemplo de esto son las películas de la llamada Época de Oro del Cine Mexicano donde actrices como Blanca Estela Pavón al lado de Pedro Infante, dan vida a personajes como "La
} 
hermanos y posteriormente con el marido, de tal forma que la mujer nunca logra ser dueña de sí misma. Su situación económica y social, ha sido inferior a la del hombre, por lo tanto, las mujeres han llegado a asumir que su dependencia y explotación son fenómenos naturales y no un resultado de cuestiones sociales (Careaga, 1987: 115). Parecería increíble pero en este país surrealista (México), es factible escuchar en la clínica cómo mujeres profesionistas, aparentemente liberadas del estereotipo clásico, se viven atrapadas en conflictos neuróticos con respecto a su sexualidad y el ser mujer, sometidas y dependientes de uno o varios varones.

Para analizar una sociedad, es necesario tomar su unidad básica: la familia. Según Díaz-Guerrero, la familia mexicana se rige por dos factores principales: la primacía del padre y el total autosacrificio de la madre, esto último le da a ella el estatus de autoridad moral y casi sagrada. La figura de la madre en esta concepción se relaciona en el mito a la mujer como madre virgen, fálica y omnipotente (Díaz-Guerrero, 1976: 35).

Los papeles que se juegan dentro de la familia mexicana se desarrollan de acuerdo a estas dos premisas socioculturales que inoculan el mito sobre la mujer. "Desde la infancia, los roles de género se establecen dentro de la familia. Se espera que las niñas sean más emocionales, que muestren virtud, pureza e inocencia. Las niñas deben jugar juegos maternales como las muñecas y la comidita, preocuparse por su imagen femenina y su belleza” (Díaz-Guerrero, 1976: 36). Desde el principio, las niñas aprenden su rol social de acuerdo a la mitificación de la mujer y la amenaza constante de ser juzgadas y denigradas si se atreven a ir en contra de las concepciones sociales que se tiene de ellas.

Una vez iniciada la adolescencia, las cuestiones sexuales son prohibidas para las niñas y la virginidad es el valor mas apreciado. Las niñas adolescentes deben mantener sus actitudes femeninas preparándose para ser buenas esposas: tiernas, maternales, religiosas y cuidadosas de nunca mostrar deseos o necesidades sexuales;

Chorreada” y “Pepe El Toro”, proyectando claramente el imaginario de género de la sociedad mexicana. 
deben mostrarse como ideales sin deseo ni castración (Rocha, 1999). A las niñas no les está permitido ver su cuerpo como un objeto sexual de placer. La gratificación sexual para las niñas es una cosa pecaminosa, algo que las haría verse como prostitutas, niñas malas. Esto se vuelve más evidente en la juventud, donde para los jóvenes varones las expresiones sexuales son abiertas sólo con prostitutas o sus equivalentes, mientras que para propósitos matrimoniales, buscan el prototipo femenino de mujeres-madres. Este proceso de selección también afecta a las mujeres, quienes tienen que mostrarse acordes con los ideales de feminidad para ser escogidas como esposas.

Es en esta etapa donde el mito de la mujer es más observable. Se plantean dos categorías de mujeres: las futuras esposas (mujeres castradas pero idealizadas y veneradas, morales y asexuales en su pureza y virginidad) y las prostitutas (fálicas y temibles, por lo mismo castradas y denigradas como objetos sexuales). En ciertos estratos de la sociedad mexicana contemporánea, las mujeres luchan en el conflicto entre sus valores y roles culturales y la influencia de los movimientos feministas que consideran que la mujer no debe jugar el papel de sumisión sino ser considerada en igualdad al hombre. Al ser influenciadas por movimientos e ideas originalmente extranjeras, parece como si estas mujeres jugaran un papel similar al de Malinche: la adoración a las ideas extranjeras en lugar de aceptar las de su propia cultura.

Siguiendo con el mito, los hombres siguen mostrando adoración hacia las mujeres que llenan el prototipo del rol femenino esperado; y denigran a aquellas que no lo cumplen. Después del matrimonio, para el hombre mexicano la esposa no es considerada un objeto sexual, sino la madre de sus hijos, sin deseo propio. Las esposas mexicanas tienen que negar sus necesidades y deseos para cumplir de manera maternal tanto con el esposo como con los hijos, denegando su castración. El maternaje mexicano es sumamente permisivo, afectivo y sobreprotector del hijo, haciendo que la madre se dedique por completo a él. Durante toda su vida, las mujeres mexicanas se ven atrapadas al no permitírseles expresar y menos aún satisfacer sus deseos (Espinoza de los Santos, 2000).

Para entender los mitos desarrollados alrededor de la figura de la mujer 
mexicana, es necesario retomar la historia de México. Desde sus orígenes, la sociedad mexicana surge a partir de la conquista de los extranjeros (los españoles: significantes culturales del Nombre del Padre), el proceso de colonización y el mestizaje, por lo que aún se encuentra en el proceso de encontrar su propia identidad nacional. Por estas razones, para entender a la mujer como mito, debemos comenzar por la primera mujer mitológica de México: La Malinche. Esta mujer, aunque es parte de la historia, se ha transformado en un mito de feminidad en la sociedad mexicana.

A pesar de que la Virgen de Guadalupe es una figura mucho más popular que La Malinche, ésta última es un personaje real en la historia de México, en cuya leyenda se proyecta un imaginario cultural de mujer particular. Estas dos imágenes, convertidas en mitos, representan las figuras femeninas de la sociedad mexicana en una rígida dicotomía donde mujer es o bien la Virgen-madre o la traidora-prostituta. La primera es una concepción idealizada de la mujer, la segunda muestra el drama de tratar de ser una mujer en un mundo gobernado por los hombres. Ambas figuras maternas integran (o deconstruyen) el concepto de mujer como objetos parciales: o se es una virgen o se es una prostituta. En el desarrollo del mito de La Malinche, se muestran ambas concepciones.

La Malinche representa la concepción universal de la mujer como objeto idealizado, completo y no castrado, madre fálica todopoderosa, que decepciona a los otros cuando muestra su falta, su deseo y su castración, por lo que es devaluada y denigrada colocada en el lugar de objeto. Se encuentran similitudes entre el mito de $\mathrm{La}$ Malinche y otros mitos bíblicos femeninos como el de Eva y Lilith, donde Lilith es la mujer originaria, con deseo propio y es suplantada por Eva, la mujer creada para el hombre, castrada y a su servicio nuevamente colocada como objeto (Schoffer y Wechsler, 1993). En México, el mito primordial sobre lo que debe ser una mujer es la Virgen de Guadalupe, mito análogo al de Eva, sin embargo, la primera mujer y madre de los mexicanos fue Malinche, quien, al igual que Lilith, ha sido denigrada como una mujer malvada. 


\subsection{La Malinche: Doña Marina, Malinalli o Malitzin (1504?-1527)}

El mito de La Malinche contiene tres leyendas en sí mismo (Florescano, 1995). La primera versa sobre el nacimiento e infancia de La Malinche, la segunda es referente a su participación histórica en la conquista y la tercera concierne a la creencia supersticiosa creada durante la colonia en la que La Malinche se convierte en La Llorona, fantasma que ronda por las calles del centro de la ciudad llorando la muerte de sus hijos. Es Octavio Paz quien a principios de la década de 1950 edita el mito dándole un lugar conceptual en la cultura mexicana.

Malinalli era su nombre náhuatl. Mujer indígena de origen noble, del pueblo de Painala, según la leyenda fue la única hija de un rey indígena. Al morir su padre, la madre contrae matrimonio con otro hombre y tiene un hijo varón. Malinalli era la heredera y sucesora al trono de su padre, por lo que para darle el trono a su nuevo marido, la madre, regala a su hija a los indios xicalango como esclava, corriendo el rumor de que había muerto, perdiendo así su herencia y el reinado de su padre. Los xicalango la venden a los indios de Tabasco quienes la regalan, entre otras 20 mujeres, a Hernán Cortés (Díaz del Castillo, 1965: 121-123).

Malinalli tenía 14 años cuando es regalada a los españoles en Pochotan. El propósito de este regalo era, según la costumbre, ofrecer a los españoles mujeres que los sirvieran en las labores domésticas y sexuales. Recordemos que a la llegada de los españoles, los indígenas pensaban que eran dioses, que según la leyenda, Hernán Cortés era Quetzalcóatl, el Dios que regresaba a liberar a su pueblo (Portilla, 1961: 27).

El cronista español Bernal Díaz del Castillo (1965) describe cómo Malinalli se involucra en los asuntos españoles en el pueblo de Chalchicuecan, donde los primeros hombres de Moctezuma hacen contacto con los españoles y Jerónimo de Aguilar, quien era el traductor oficial, no entendía su lenguaje. Los enviados de Moctezuma hablaban náhuatl y Jerónimo de Aguilar solo hablaba maya. El cronista narra que Malinalli se presentó con los hombres de Moctezuma traduciendo al maya para Jerónimo de Aguilar. Ante esta escena, Cortés libera a Malinalli y la nombra su secretaria y traductora 
particular. En poco tiempo, Malinalli se convierte en la pieza más importante de Cortés para conquistar a los aztecas, ya que también aprende español y pronto traduce del maya y del náhualt a la lengua de los conquistadores.

De linaje real, Malinalli era una indígena culta, inteligente sociable y abierta, como la describe el cronista español. Debido a esto Malinalli pasa de ser una esclava indígena y concubina de un soldado español a convertirse en secretaria, traductora y amiga íntima de Hernán Cortés. Posteriormente se convierte también en su pareja y amante, dándole un hijo bastardo. De acuerdo con la leyenda, Cortés se enamora de Malinalli, pero había contraído nupcias en España con otra mujer, por lo que su relación, sea cual fuera, se mantuvo en el amasiato.

Al convertirse en colaboradora de Cortés, Malinalli abandona su nombre náhuatl y es bautizada por los españoles como Doña Marina; mientras los indígenas la llaman Malitzin, que en náhuatl significa Señora Malinalli. Posteriormente, los mismos indígenas nombran a Cortés Malinche, que significa Señor Malitzin. Para los indios, Malitzin era una diosa que hablaba el lenguaje de Quetzalcoatl (Cortés) y era tratada como deidad. Malinalli era admirada y respetada tanto por los españoles como por los indígenas por lo que no resulta extraño que tanto españoles como indígenas la llamaran Señora. Es así como siendo admirada por los españoles por su belleza, arrogancia e inteligencia, y por los indios por ser la mensajera de Quetzalcoatl, Malitzin se consolida como una figura histórica y mítica.

Para los indígenas (Valiant, 1965: 172), Malitzin tenía poderes sobrenaturales y se le relacionaba con la Diosa Madre, madre de todas las madres Cihuacóatl Tonantzin $^{2}$ y con Coatlicue ${ }^{3}$. Durante la colonia, el mito de Malitzin llega a su fin cuando se convierte en La Llorona. Una vez consolidada la conquista, los indígenas se

\footnotetext{
${ }^{2}$ La Mujer Serpiente; Diosa de la Tierra, de la fertilidad, del nacimiento y de la muerte durante el parto. Posteriormente, la Virgen de Guadalupe aparecerá en el Tepeyac, lugar donde se llevaban a cabo los rituales para esta diosa. De hecho, la Virgen de Guadalupe también toma el nombre de Tonantzin.

${ }^{3}$ Falda de Serpiente, Diosa de la Tierra, asociada a la Primavera y madre de Huitchilopochtli, Dios principal de los aztecas. El mito de Huitchilopochtli es muy similar al mito bíblico de Jesús, quien nace de una virgen, siendo el hijo de Dios.
} 
percatan de que Cortés no es Quetzalcoatl y que los españoles no son dioses. Al ver su cultura destruida por los españoles, Malitzin es juzgada como la traidora de su gente. Así, durante la colonia aparece el mito de una mujer que llora a la media noche en el centro de la Ciudad de México ${ }^{4}$. Esta mujer pena por la muerte de sus hijos, a los cuales ella misma entregó. Al unir en el inconsciente colectivo los mitos de Malitzin, Cihuacóatl y La Llorona, queda claro en el simbolismo pagano quién es la madre mitológica de México, su primera dama.

En 1950, Octavio Paz, reescribe el mito de Malitzin nombrándola Malinche, nombre utilizado por los indígenas para nombrar a Cortés. Octavio Paz, en su libro Laberinto de la Soledad, indica que los mexicanos somos hijos de la Chingada, hijos del abandono y la orfandad. De acuerdo a su propia interpretación del mito, La Malinche como madre de la nueva raza (los mexicanos) es La Chingada en persona. La frase hijos de la Chingada significa, de acuerdo con Paz, hijos de la mujer violada, de la mujer inmoral: ésa es La Malinche.

En el diccionario de la Real Academia de la Lengua Española (1983), chingado significa rabón, animal al que se le ha cortado el rabo, al que se molesta, molestado, o perdedor. Gramaticalmente, chingada (femenino de chingado) es una alusión en el inconsciente colectivo, al complejo de castración en la mujer. Cuando a uno le dicen que es hijo de la chingada, se pone en evidencia la castración de la madre.

Además de Paz, otros pensadores mexicanos han denigrado la figura de Malitzin: “La Malinche es la traidora que desprecia a su gente considerándolos inferiores y se humilla ante la superioridad de los conquistadores” (Rubén Salazar Mallen); “somos los hijos de la prostituta del conquistador” (Carlos Fuentes); algunos incluso la llaman "la gran prostituta pagana” (Roger Bartra).

La herencia de Malitzin y su maldición caerá sobre cualquier mujer mexicana que se atreva a seguir su ejemplo de mujer arrogante, culta, inteligente y bella (fálica); aquellas que no asuman el idealizado rol de abnegación y sumisión del maternaje y

\footnotetext{
${ }^{4}$ El lugar donde la gente dicen que La Llorona se aparece es alrededor del actual Palacio de Gobierno, que antiguamente era el Templo Mayor.
} 
prefieran creer en su propio deseo. El mito colonial de La Llorona es la versión de la culpa, donde Ella reconoce su pecado y vagabundea con su dolor y su pena tratando de pagar su culpa. Este mensaje está dirigido a las mujeres que se atrevan a seguir los pasos de Malitzin, a esas malas mujeres: traidoras, prostitutas; serán condenadas al sufrimiento eterno y a la culpa.

\subsection{Análisis del Mito}

b) Malinalli es una princesa India, heredera al reinado de su padre.

$\frac{\text { Malinalli }}{\text { princesa }} \rightarrow \frac{\text { Malinalli }}{\text { Hija del Rey }} \rightarrow \frac{\text { Malinalli }}{\text { heredera }} \rightarrow \frac{\text { Malinalli }}{a} \rightarrow \frac{\text { Malinalli }}{S}$

La historia comienza en lo que Freud plantea como la opción de un desarrollo heterosexual sano en la mujer: la hija como pareja del padre, significada por su nombre y con la madre como rival. El significante princesa refiere a la mujer a dos significados: hija del rey y por lo tanto su heredera. Siendo el padre Rey, tiene la atribución fálica del poder y del saber. Las princesas son también figuras edípicas (Betelheim, 1976: 97), las hijas favoritas del rey, y por lo tanto, poseedoras del falo paterno. Siendo la heredera del reinado del padre, la mujer- princesa posee la atribución fálica, siendo un objeto de deseo $(\boldsymbol{a})$ y potencialmente un sujeto deseante $(\mathbf{S})$.

b) Después de la muerte de su padre, Malinalli es regalada como esclava.

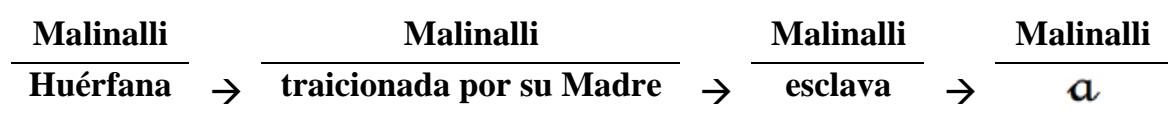

Siguiendo el orden de la regresión infantil, la segunda parte del mito evidencia 
el conflicto de separación con la madre ampliamente trabajado por Klein y Bleichmar entre otros. La muerte del padre queda significada para la niña por el arrebato de su posición como sujeto. La madre traiciona a su esposo muerto, al casarse con otro hombre, y traiciona también a su hija con un hijo varón. Al dejar de ser el objeto de deseo, de investidura libidinal del padre, la hija queda castrada, y aún más, aparece un rival (el nuevo marido-hijo) que sí es deseado por la madre. El hijo varón se convierte en el falo materno. El hijo es ahora el nuevo heredero que reemplaza a la hija y la castra. La mujer castrada convertida en objeto es regalada para servir a otros hombres, devaluada y denigrada. La mujer se convierte en un objeto para el deseo de otros $(\boldsymbol{a})$.

La oposición se establece entre el hijo (hombre) como falo materno, y la hija (mujer) castrada. Su posición como sujeto en falta la lleva a buscar el falo perdido en otros hombres quienes se convierten en fantasmas del padre.

Por otra parte, al ser una hija traicionada, la mujer se convierte en una madre potencialmente traidora. Esta experiencia la predispone a traicionar a sus propios hijos, identificándose con el objeto malo (la madre traidora).

Este fragmento del mito se asemeja a otras historias del inconsciente colectivo, como por ejemplo el clásico cuento de Blanca Nieves o la historia de Cenicienta. En ambas historias, la hija amada por el padre es arrancada de su posición en la realeza a la muerte de éste. Muchos autores (Betelheim, 1976: 8) han interpretado la figura de la reina bruja o la madrastra como la madre envidiosa de la belleza y juventud de la hija (Blanca Nieves) o bien de su posición real (Cenicienta). Se trata de un conflicto de rivalidad entre mujeres donde una elimina a la otra en tanto rival edípico. Se trata de la envidia hacia la otra mujer, tanto de la hija hacia la madre como de la madre hacia la hija.

Los años que transcurren en la vida de Malinalli como esclava nos son desconocidos. Cuando reaparece es para convertirse en protagonista de la historia. Malinalli es representada como una mujer particular quien, en su condición de esclava y mujer, hecha mano de su creatividad para cambiar su posición de objeto a hacerse de un lugar como sujeto. 
Subjetividad femenina más allá de la diferencia anatómica de los sexos

c) Malinalli se convierte en traductora, secretaria y amante de Cortés.

\begin{tabular}{|c|c|c|c|c|c|c|}
\hline Malinalli & & Malinalli & & Malinalli & & Malinalli \\
\hline traductora & & conocimiento & & lenguaje & & \\
\hline secretaria & $\rightarrow$ & asistente & $\rightarrow$ & Igualdad & $\rightarrow$ & \\
\hline amante & & mujer sexual & & mujer amada & & $S$ \\
\hline
\end{tabular}

En la búsqueda del fantasma del padre, la mujer muestra las habilidades necesarias para poseer el falo. Utiliza su inteligencia y belleza para acercarse al fantasma. Cortés en su posición de varón, conquistador e imagen de Quetzalcóatl, aparece evidentemente como un $\operatorname{Amo~}(\mathscr{Q})$, un Otro poderoso y fálico.

La mujer deniega su castración e interfiere a través de lo Simbólico (el lenguaje) hacia el Imaginario en la relación con el Otro. Habiendo sido castrada previamente por la madre, se acerca a la figura paterna, quien posee el falo. Aprende un nuevo lenguaje, se introduce en Lo Simbólico en un verdadero acto creativo, como lo señala Lacan. Al obtener una atribución fálica $(\varphi)$, la mujer se convierte en la madre que introduce el Nombre del Padre (el español, lengua de Cortés) en el discurso a sus hijos (los indios).

Por otra parte, juega el papel de pareja de un hombre, no en la forma convencional de sumisión, sino como iguales. Siendo su amante, la mujer toma el lugar del objeto del deseo del hombre, siendo reconocida como mujer sexual; sin embargo, no aparece como un ser devaluado en su sexualidad ni en su persona. Así, la mujer se presenta como un ser sexual asumiendo una castración y mostrándose como sujeto deseante (S).

Es en este fragmento de la leyenda donde Malinalli aparece como una mujer con las características descritas por Benjamin y Bassin. Una mujer que logra resolver los conflictos edípicos con el padre identificándose en lo masculino con Cortés y los españoles al aprender su lenguaje, pero manteniendo sus atributos femeninos e 
indígenas en su relación amorosa con Cortés y su papel de traductora frente a los Indios.

También en este sentido Malinalli aparece como una mujer dentro y fuera de la ley: entre dos culturas haciendo la ley relativa, como señala Lacan. Nombrada Señora tanto por los españoles como por los indígenas. Cambia su nombre y Cortés es nombrado a partir de ella.

d) Malinalli es asociada con las Diosas Madres, Cihuacóatl Tonantzin y Coatlicue.

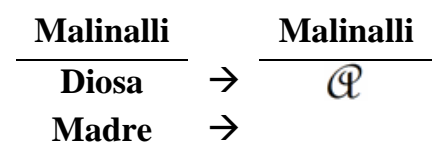

La mujer es ahora vista por los hijos (los indígenas) como imagen idealizada. Al ser relacionada con una diosa, se convierte ella misma en un Amo. El significante Diosa se significa por el falo. Su castración es denegada y la mujer se convierte en una madre fálica, no castrada, como en los mitos donde las vírgenes dan a luz representando en el inconsciente la fantasía de la madre fálica que no necesita de nada más que del hijo para ser madre. Se deniega la ley del padre quien es esa ahora sujeto a la ley de la madre, y no a su deseo. ${ }^{6}$

En este fragmento, Malinalli pierde nuevamente su lugar como sujeto (S) y es resignificada por la cultura en un lugar idealizado como Amo, como gran Otro (Q) ). Es evidente que éste es el lugar otorgado por la cultura a la mujer-madre: fálica, omnipotente y por lo mismo temida.

\footnotetext{
${ }^{5}$ Las dos diosas a las cuales se asocia Malinalli son madres vírgenes. A pesar de que el concepto de virginidad no se maneja en la cultura azteca como en la cultura occidental, ambas diosas son creadoras de vida sin necesitar de una figura masculina.

${ }^{6}$ En este momento, Cortés es llamado Malinche, refiriéndolo en relación a Malitzin. Es él quien lleva el nombre de ella, contrario al concepto convencional donde es la mujer quien lleva el nombre del hombre, como título de propiedad (sea el de su padre o el de su marido). De hecho, los indios fueron más bien conquistados por Malitzin que por Cortés. Ella lo introduce a la cultura y creencias de los indios. Es por eso que se le juzga como traidora.
} 
Subjetividad femenina más allá de la diferencia anatómica de los sexos

e) Durante la Colonia Malitzin se convierte La Llorona.

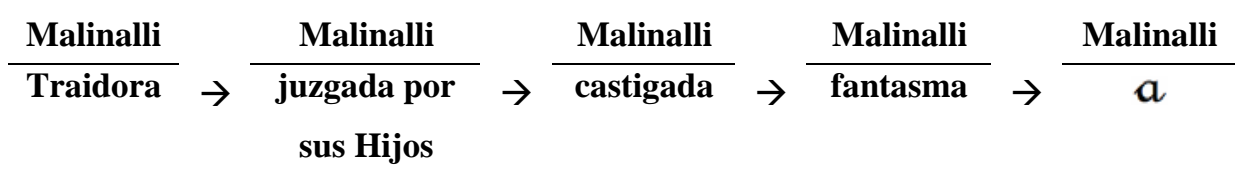

En este fragmento queda claro cómo la mujer es transformada en el blanco de las ansiedades infantiles de un pueblo conquistado. Una vez que la ilusión de la denegación de la castración de la madre cede, el significante de la falta surge nuevamente. La mujer es ahora vista como castrada, como un ser en falta y así el Otro (los indígenas) se siente traicionado por ella. Ante la frustración causada por la decepción ante la condición de la madre con la herida narcisista causada al darse cuenta que no se es el falo de la madre, ésta es juzgada y castigada mostrando su falta y mostrada nuevamente como objeto, esta vez de rechazo $(\mathfrak{a})$.

El juicio al que es sometida la mujer tiene por objeto generar en ella culpa y la aceptación de su condición como castrada y mala. El castigo consiste en la pérdida de su condición corpórea, es privada de su propio cuerpo y condenada a sufrir por sus pecados. Este es el discurso de la culpa, del sufrimiento y abnegación femeninos tan populares en nuestra cultura. La abnegación de La Llorona semeja una mascarada, una exageración del estereotipo de género femenino. Ambas reacciones son un acting; de la culpa inconsciente por usurpar el lugar fálico como lo señala Rivière y una reacción frente a las ansiedades derivadas de la sexualidad perversa infantil, como lo explica Kaplan.

f) Malinalli es llamada La Chingada, la castrada.

$\frac{\text { Malinalli }}{\text { La Chingada }} \rightarrow \frac{\text { Malinalli }}{\text { castrada }} \rightarrow \frac{\text { Malinalli }}{\text { denigrada }} \rightarrow \frac{\text { Malinalli }}{a}$


El significante Chingada está significado por la denigración de la mujer, como un insulto hacia ella, una agresión, y sobre todo, una etiqueta de castración. Una vez que la mujer deja de ser dueña de su cuerpo, también queda castrada de los deseos sobre ese cuerpo. Así, es despojada de su deseo sexual y su capacidad de goce, se le asume como violada, ocupando el lugar de un objeto sexual, una prostituta.

Después de castigar a la falsa mujer, concebida ahora como castrada y violada, es denigrada y ofendida. La reacción ante la frustración de no ser el deseo del Otro (madre-mujer) es agresiva y destructiva. Y esa es la reacción que prevalece ante las mujeres que siguen su deseo de tener (no de ser) el falo y son vistas como fálicas. La mujer fálica es vista como amenazante, ya que se asume que está predispuesta a la traición, al abuso, la manipulación y la mentira.

A pesar de ser temidas, las mujeres fálicas son también envidiadas. El miedo y la envidia llevan a la fantasía de la destrucción del objeto. La Madre Buena cambia a ser la Madre Mala fallando así en la integración de la mujer como objeto completo.

La Llorona y La Chingada son ambas objetos parciales y figures castradas que no pueden ser integradas como una sola. La mujer (Malinalli) queda escindida entre la madre abnegada y la prostituta. Sin embargo, el mito como un todo integra las dos imágenes en una complejidad de imágenes y roles de las posiciones jugadas en el ser mujer y la manera como es significada en el discurso de los Otros.

El tránsito de la transformación de imágenes va de la niña que fue traicionada por una madre que toma su lugar con Otro varón, a la mujer esclava, objeto de servicio de los hombres, a la única posibilidad de ser mujer en Lo Simbólico, en su identificación masculina y formando una pareja sexual con el varón. Llegando este punto, los hijos idealizan a la mujer-madre para posteriormente, al no soportar una madre con deseo propio, la satanizan y despojan de ese cuerpo sexual, escindiéndola en dos objetos polarizados: La Madre y La Prostituta. 


\section{Descomposición Estructural}

\begin{tabular}{|c|c|c|}
\hline $\begin{array}{l}\text { S Sujeto Deseante } \\
\text { MUJER } \\
\text { En relación a un } \\
\text { varón }\end{array}$ & $\begin{array}{l}\text { a Objeto de Deseo } \\
\text { MADRE MALA } \\
\text { Traidora-Prostituta } \\
\text { En relación a otra mujer }\end{array}$ & $\begin{array}{l}\mathcal{Q} \text { Gran Otro - Amo } \\
\text { MADRE BUENA } \\
\text { Diosa-Señora } \\
\text { En relación a los “hijos" }\end{array}$ \\
\hline \multicolumn{3}{|l|}{$\begin{array}{l}\text { Malinalli es una } \\
\text { princesa }\end{array}$} \\
\hline & $\begin{array}{l}\text { Malinalli es regalada por su } \\
\text { madre como esclava }\end{array}$ & \\
\hline \multicolumn{3}{|l|}{$\begin{array}{l}\text { Malinalli es la } \\
\text { traductora, secretaria y } \\
\text { amante de Cortés }\end{array}$} \\
\hline & & $\begin{array}{l}\text { Malinalli (Malitzin) es vista } \\
\text { como una Diosa ante los indios }\end{array}$ \\
\hline & & $\begin{array}{l}\text { Malinalli (Doña Marina) es } \\
\text { llamada Señora por los } \\
\text { españoles }\end{array}$ \\
\hline & $\begin{array}{l}\text { Malinalli (Malinche) se convierte } \\
\text { en La Llorona. }\end{array}$ & \\
\hline & $\begin{array}{l}\text { Malinalli (Malinche) es llamada } \\
\text { La Chingada, la castrada. }\end{array}$ & \\
\hline
\end{tabular}

En la primera columna, la mujer es un ser real, un personaje histórico. Ella existe como princesa, traductora, secretaria y pareja. Tiene un rol definido por sí misma: princesa por ser la hija del rey, traductora y secretaria por sus habilidades, y amante en su condición de mujer sexual.

Tanto en la posición de hija como en la de amante, la mujer esta relacionada al deseo del hombre hacia ella (padre o pareja). Estando en la posición de sujeto, la mujer asume su propia falta, la muestra y vive de acuerdo a ésta.

Es el amor lo que hace de esta mujer ella misma. El amor del padre, el amor del hombre. Siendo un sujeto de deseo, ella es vista como un individuo y reconocida como ser, no como idea o concepto. Es el reconocimiento de la ley del padre que permite al sujeto reconocer la falta y la castración, llevando a la mujer a operar desde la 
posición de la falta haciendo que su deseo sea ser deseada por el Otro en el discurso de la histérica (Lacan, 1966: 125). El aceptar que el ser humano no es completo, que hay una falta y búsqueda por el falo para completarse es aceptar la ley del padre la ley del falo como la marca de la diferencia entre los sexos y el poder simbólico. Este sería el caso más adaptativo, sin embargo, asumir este lugar genera envidia y enojo en el Otro que lleva a las posiciones de la segunda columna. Esta segunda columna presenta dos imágenes superpuestas: La Mujer y La Madre.

Aquí la mujer es colocada como un objeto malo. La madre es vista como traidora de sus hijos al preferir a un hombre-pareja como objeto de su deseo en lugar de escoger al hijo. Ella es juzgada por su deseo y castrada por ello. Este es el lugar dado a la mujer por el Otro (cultura) como reacción ante el hecho de que ella asuma su deseo. Es una reacción provocada ante la tentativa de perder el fantasma de ser el deseo de la madre, su falo.

Al mostrar su deseo, la mujer falla como objeto idealizado y es castrada por el Otro (madre-cultura). En esta nueva posición, la mujer se convierte en objeto de agresión de ese Otro que se sintió traicionado por ella. Por lo tanto es castrada de su deseo y denigrada por el discurso de la culpa. La mujer es ahora vista como una prostituta, o bien faltante de su propio cuerpo (al convertirse en fantasma o en concepto).

En la última columna, la mujer es vista como la madre idealizada, la Madre Buena y fálica quien cuida de sus hijos. La Virgen de Guadalupe se coloca en esta columna en una continuidad colonial del mito de la mujer. Como madre virgen, la mujer no necesita de un hombre (falo) para ser madre (el hijo es el falo). Es la denegación de la castración femenina y el asumir que el Otro es el deseo de la madre, su asujet, lo que la hace perder su propia humanidad. Esta es la denegación perversa de la ley de padre, donde la falta es negada y las estructuras narcisistas prevalecen como en la cultura mexicana.

A través de la integración del mito, la síntesis de las últimas dos columnas lleva a la oposición binaria primordial de los significantes de la mujer mexicana. Como 
en un espejo, la concepción social es una imagen especular (o una interpretación) de la mujer real. Solo hay una mujer real, la que se asume a sí misma como un ser humano en falta y deseante (castrada). La sociedad, estando en la posición del Otro (cultura), funciona como una estructura perversa que deniega la castración de la mujer creando una imagen falsa de la mujer fálica. Aún mas, este Otro social emite juicios morales ante estas dos figures: así la mujer castrada es denigrada y ofendida en su sexualidad, llamada prostituta; mientras que la falsa mujer fálica es idealizada y venerada por sus virtudes morales asexuales que asumen su pureza y virginidad.

La figura de la virgen es significada por la denegación de la ley del padre como la marca de la diferencia entre los sexos. Ya que la virgen no necesita de un hombre, no tiene deseo sexual, no está castrada, debe tener el falo. Éste es el concepto de la mujer creado por los hombres, luego entonces aceptado y esperado por ellos: dulce, pura, trabajadora en el hogar, fiel, madre amorosa y esposa abnegada.

Estas concepciones provienen del discurso del Otro. En este caso el significante Otro se encuentra significado por la cultura Mexicana, una cultura creada por y para hombres. Se trata de hombres hablando sobre las mujeres y éstas asumiendo sus concepciones a través del discurso social. Los hombres, como hijos, no pueden admitir la idea de la castración materna. Las mujeres pueden estar castradas pero no La Madre, ya que aceptarlo sería aceptar que ellos no son su falo.

\section{Nuevas propuestas}

Socialmente, desde la perspectiva del patriarcado, la mujer es vista dicotómicamente: hay dos tipos de mujer, la madre virgen y la prostituta. Freud lo planteaba en 1910 en sus “Contribuciones a la Psicología del Amor”. Klein conceptualiza la ambivalencia ante la figura femenina en sus nociones de la Madre Buena y la Madre Mala. 
A partir de los autores revisados, podemos plantear que el patriarcado funciona como defensa frente al enigma de la mujer y su imagen idealizada. Así se generan mitos para sostener al padre patriarcal en decadencia.

En la relación con las otras mujeres, se conserva la dicotomía propia de la cultura ya que el conflicto con la madre omnipotente es propio de ambos sexos. La rivalidad con las otras mujeres y con sí misma es uno de los conflictos principales en la construcción de la subjetividad femenina: ser una misma y no la madre.

Para esto es importante la constitución de una pareja, heterosexual u homosexual, que marque la diferencia entre la mujer y su madre. Una diferencia no evidenciada en la anatomía sino en lo simbólico. Es necesario un tercero (padre, pareja o analista; hombre o mujer) que signifique al sujeto femenino de manera distinta a la significación materna.

Uno de los problemas de la teoría psicoanalítica con respecto a la perspectiva de género es que en la clínica se observan las psicopatologías y a partir de éstas se pretende explicar los fenómenos normales. La psicopatología es en este sentido, “una enajenación del rol sexual”(Kaplan, 1941: 25).

Por otra parte, el falo como significante primordial en la teoría psicoanalítica es un obstáculo para la comprensión del género, ya que el falo es una construcción en lo Simbólico que cruza el poder y el género en un discurso “androcéntrico, heterosexista y capitalista” (Campbell, 2000: 1). A partir de lo anterior, la problemática fundamental para comprender la subjetividad femenina es aproximarse al sentido del ser mujer en una cultura, una sociedad y un momento determinado. Para lo cual habrá que deconstruir varios argumentos de la teoría psicoanalítica con respecto a la mujer y la feminidad. La pregunta histérica (“¿qué es una mujer?”) habría que plantearla en términos de “¿cuál es el sentido de ser-ahí una mujer?”. Así mismo habría que preguntar por el ser del varón contemporáneo.

La respuesta a ambas preguntas en la teoría psicoanalítica son fantasmas. Fantasmas emitidos por el sexo opuesto, por el Otro. En el caso de la mujer, la pregunta la resuelve el mismo fantasma de la histérica; o bien el fantasma de la maternidad. En el 
caso del hombre, la pregunta es encubierta por el fantasma del analista (como partenaire de la histérica, (André, 2002) y el fantasma de El padre.

No hay relación sexual porque no hay complementariedad entre los sexos, ya que los discursos son androcéntricos y no permiten un significante para La Mujer. Sin embargo, en un discurso ginocéntrico (Campbell, 2000: 113) tampoco hay significante para El Hombre. No se puede definir a un sexo sin el otro. Se tienen que definir a partir de la pareja.

Podemos pensar en 8 tipos de parejas: Hombre/Mujer (pareja heterosexual), Hombre/Hombre (pareja homosexual), Mujer/Mujer (pareja lésbica), Hombre/Padre (pareja edípica homosexual masculina), Hombre/Madre (pareja edípica masculina), Mujer/Madre (pareja edípica homosexual femenina); Mujer/Padre (pareja edípica femenina), y Hermana(o)/Hermana(o) (pareja filial).

$\mathrm{Al}$ interior de estas parejas la pregunta por el ser se formula en el sentido “¿qué soy-ahí (hombre o mujer) para el Otro?”. Y a partir de su respuesta se contesta qué soyahí (hombre o mujer) para mí mismo. Resultan pues importantísimas dos variables en estas interrogantes: el tiempo en el que se realiza la pregunta y la relación (con el Otro) en la cual se pregunta.

El problema de la pareja es que la relación sexual se topa con dos fenómenos obstaculizantes: el amor y el poder. En ambos, tradicionalmente, la mujer (o quien ocupa la posición femenina-pasiva) es objeto del deseo del Otro (dialéctica del amo y el esclavo: $\boldsymbol{a}-\mathscr{Q}$ ). Por lo que la única salida al problema de la pareja (de la relación sexual) es el reconocimiento de la necesidad del Otro como complemento, no como Amo.

Las propuestas para resolver las problemáticas planteadas son las siguientes:

1. Propuesta Evolutiva. Consiste en plantear que, para acceder a la subjetividad del ser hombre y del ser mujer, es necesario realizar un análisis de la historicidad del sujeto. A partir de esto, la subjetividad del ser mujer u hombre dependerá de su historia y la manera como se vive a sí misma/o con esta historia. Dentro de la historia del sujeto, aparecen los fantasmas de la significación cultural y los fantasmas del género, que serán 
los fenómenos a partir de los cuales habrá que analizar el sentido del ser-ahí mujer/hombre. Ambos géneros, antes que ser sexuados son sujetos, que construyen su subjetividad a partir de una historia vivida y contada por ellos mismos y/o por Otros. En este sentido, la solución al devenir mujer (o devenir hombre) será una contraparte infantil (niña/niño), que en el caso de la mujer versa sobre la diferenciación en la relación narcisista con la madre. Es decir, que no es la dialéctica con el hombre lo que define a la mujer en el sentido de su ser, (como en el discurso de la histérica) y viceversa, sino que cada mujer/hombre se crea una identidad a partir de los fantasmas de su historicidad como mujer/hombre. La consolidación del ser mujer no va en contraparte con el no-ser-hombre, sino con un dejar-de-ser-niña y no-ser-la-madre.

2. Propuesta de Complementariedad. Consiste en la posibilidad del reconocimiento de la necesidad del otro sexo no como amo, sino como complemento. Es una propuesta de equidad. Sin embargo, una mujer no puede mostrarse como mujer ante un hombre dejando fuera la lucha de poderes (es decir, sin competir), sin antes asumirse ella misma como mujer desde su propia historia: sentirse mujer. El hombre tampoco puede mostrarse como hombre ante una mujer sin antes asumirse él mismo y sentirse hombre. 


\section{BIBLIOGRAFÍA}

André, S. (2002): ¿Qué quiere una mujer? México, Siglo XXI.

Bassin, D. (1985): "Beyond the he and the she: toward the reconciliation of masculinity and femininity in the postoedipal female mind”, en Journal of American Psychoanalytic Association, 44S:157-190.

Benjamin, J. (1991): "Father and Daughter: Identification with the difference- a contribution to gender Heterodoxy”, en Psychoanalytic Dialogues, 1:277-299.

Betelheim, B. (1976): Psicoanálisis de los Cuentos de Hadas. Buenos Aires, Paidós.

Bleichmar, E. (1985): El Feminismo Espontáneo de la Histeria. México, Fontana.

Campbell, J. (2000): Arguing with the Phallus. Feminist, queer and postcolonial theory, a psychoanalytic contribution. London, Zed Books.

Careaga, G. (1987): Mitos y Fantasías de la Clase Media en México. México, Océano.

Beauvoir, S. de (1949): El Segundo Sexo. México, Siglo XXI.

Díaz del Castillo, B. (1965): Historia Verdadera de la Conquista de la Nueva España. México, Fernández Editores.

Díaz-Guerrero, R. (1976): Psicología del Mexicano. Descubrimiento de la Etnopsicología. México, Trillas.

Diccionario de la Real Academia de la Lengua Española (1983). México, Ed. Patria.

Espinoza, A. Santos, E. (2000): La sexualidad de la mujer mexicana: un análisis psicológico. México, Facultad de Psicología UNAM.

Ferrón, L E. (2006): ¿Y los Hombres?: Ensayo Psicoanalítico Sobre la Masculinidad. Conferencia presentada en las Jornadas Internacionales de Género y Psicoanálisis. Buenos Aires, Agosto, 2006.

Fink, B. (1996): “Perversion”. En: A clinical introduction to lacanian psychoanalysis. Cambridge, Harvard University Press.

Florescano, E. (1995): Mitos Mexicanos. México, Ed. Aguilar.

Fraisse, G. (1996) : La difference des sexes. Presses Universitaires de France.

Freud, S. (1980): Obras Completas. Buenos Aires, Amorrortu. Incluye: 
— (1895): “A Propósito de las críticas a la neurosis de angustia”. Vol III.

- (1896): "Nuevas Puntualizaciones sobre las Neuropsicosis de Defensa”. Vol. III p. 167

— (1905): “Tres Ensayos de Teoría Sexual”. Vol VII.

- (1910): "Sobre un tipo particular de elección de objeto en el hombre (Contribuciones a la Psicología del Amor, I)”, Vol. XXI.

- (1933): “33a conferencia: La feminidad”. Vol XXII.

González de Chávez, M.A. (1998): Feminidad y Masculinidad. Subjetividad en el Orden Simbólico. Madrid, Biblioteca Nueva.

Kaplan, L. (1941): Perversiones Femeninas. Las tentaciones de Emma Bovary. Buenos Aires, Paidós.

Lacan, J. (1956): La Pregunta Histérica. En El seminario de Jacques Lacan, Libro 3: Las Psicosis. Buenos Aires, Paidós.

- (1966): Los Escritos de Jacques Lacan I. México, Siglo XXI.

Mitchell, J. (2000): Mad men and Medusas. London, Penguin.

Portilla, L. (1961): La visión de los vencidos. México, Fondo de Cultura Económica.

Reich, W. (1929): Analysis of Character. Buenos Aires, Paidós.

Rivière, J. (1929): “Womanliness as a masquerade”, en Tripp A (eds). Gender. Londres, Palgrave.

Rocha, T. (1999): Roles de género en los adolescentes mexicanos y rasgos de feminidad y masculinidad. México, Facultad de Psicología UNAM.

Schoffer, D. y Wechsler, E. (1993): La Metáfora Milenaria. Una Lectura Psicoanalítica de la Biblia. Buenos Aires, Paidós.

Tort, M. (2005): Fin du Dogma Paternelle. Aubier Psychanalyse, Paris.

Vailant, G. (1965): La Civilización Azteca. México, Fondo de Cultura Económica.

Verhaeghe, P. (1997): ¿Existe la Mujer? Buenos Aires, Paidós. 